\title{
Ética, Comunicação e Jornalismo
}

\author{
Ethics, Communication and Journalism \\ Ética, comunicación y periodismo
}

\section{Entrevista com Juarez Tadeu de Paula Xavier}

\author{
Realizada por João Nery \\ Faculdade Paulus de Tecnologia e Comunicação - FAPCOM \\ $<$ joao.nery@fapcom.edu.br>
}

A Revista propôs ao Prof. Juarez Xavier uma reflexão acerca do tema da ética ligada à comunicação e ao jornalismo, áreas em que atua como pesquisador e docente na Unesp (Câmpus Bauru).

O Prof. Juarez estabelece relações entre aspectos da história contemporânea e a política, além de questões de cunho racial, na medida em que sua interpretação se insere na discussão de raça, conectando aspectos teóricos à militância antirracista na qual o entrevistado atua. Como ativista do movimento negro e cidadão, o Prof. Juarez Xavier tem sido protagonista. Dois eventos marcam sua trajetória nesse contexto: o primeiro foi a pichação no banheiro da faculdade de comunicação da Unesp Bauru com a frase "Juarez macaco", que teve grande repercussão na universidade e também na imprensa brasileira; o segundo, em quem o professor foi atacado no estacionamento de um supermercado, em Bauru, por um homem que o esfaqueou, em pleno dia da consciência negra.

João Nery: Como o senhor define a ética e a relação desta com a comunicação?

Juarez Tadeu de Paula Xavier: No aspecto lato sensu, é o respeito à dignidade das condições da vida, em todas as suas dimensões, tangíveis e intangíveis. No aspecto stricto sensu, na comunicação é a preservação da esfera pública de debate, com pluralidade de fontes, pontos de vista e plataformas midiáticas, para a preservação do Estado democrático de direito. Compreendendo essas duas dimensões condicionadas pelas precondições históricas, no país, tais como o genocídio indígena e a escravização africana, a violência do colonialismo e o apartheid social, bases das profundas contradições das desigualdades abissais que marcam a carne e a alma do país. Esse cenário criou um sistema de privilégios, para um grupo minoritário da sociedade, e um sistema de exceção, para a maior parte da população. Por essa razão, no processo democrático inaugurado pela Constituição de 1988, foram regulamentados, no texto constitucional, os direitos e deveres da comunicação, que orientam as normas de regulação dos entes corporativos e dos segmentos profissionais. No campo da deontologia da comunicação, há distinções éticas entre as atividades profissionais, sem que essas firam o diploma legal. As atividades da publicidade podem, dentro das regras legais e da autorregulamentação, projetar conceitos, sem o rigor da reprodução factual da realidade observável. Já o jornalista deve se 
ater aos fatos possíveis de serem compartilhados para além das suas subjetividades. Portanto, são atividades que observam valores éticos gerais, na preservação dos fundamentos da democracia, e singulares, na diversidade profissional encapsulada pela comunicação, com estreita relação dialógica entre esses dois sistemas de valores éticos, o universal - constituinte - e o particular - códigos e mecanismos de regulação das atividades no universo profissional.

João Nery: Como jornalista, é possível definir questões éticas na produção, na circulação e no consumo da notícia?

Juarez Tadeu de Paula Xavier: Sim! Os códigos de ética e deontológico da atividade profissional apontam esses princípios, que devem prevalecer em todo o fluxo da produção jornalística, da pauta à fruição, ao consumo da notícia. Princípios com dimensões epistêmicas, sobre a produção de uma informação válida para as relações democráticas, teóricas, sobre a diversidade da cobertura em diversas áreas do saber, técnicas, sobre os procedimentos de captação, edição e difusão de informação, e ético-deontológicos, sobre a responsabilidade social da atividade profissional do jornalista. Esses princípios sofreram impactos das mudanças sociais desde o século XIX e têm merecido, em função dessas mudanças, vigilância permanente por parte dos segmentos democráticos e progressistas da sociedade. No contexto brasileiro, com o fim da obrigatoriedade do diploma para o exercício profissional, essa prerrogativa passou a ser da empresa, que impõe seus valores éticos, desuniversalizando cânones construídos pela experiência acumulada nas redações, por gerações de jornalistas que tinham nesse espaço uma relação transgera- cional, que compartilhavam aprendizados. Um ponto de inflexão para essa mudança foi a greve geral dos jornalistas em 1979. A partir desse período, várias medidas foram adotadas, entre elas a desregulamentação que, do nosso ponto de vista, fragilizou a vigilância ética no fluxo de produção de informações, com impactos negativos para a sociedade, haja vista que, no último processo eleitoral, elegeu-se um candidato com um histórico de baixa produção congressional e uma relação desidratada com os valores democráticos e dos direitos humanos, sem que houvesse uma cobertura mais assertiva sobre essa candidatura. Passados alguns anos, conclui-se que, com a votação no Supremo Tribunal Federal, condenou-se um ex-presidente da República sem provas, e em um fórum sem legitimidade para esse fim. Uma cobertura assertiva, independente, crítica e responsável teria impedido a eleição de um projeto de desmonte de direitos sociais, trabalhistas e previdenciários, e um processo de mortes evitáveis em escala industrial, em razão da ausência de políticas públicas de enfrentamento à pandemia. No futuro, deve-se avaliar em profundidade o papel da imprensa, com raras exceções, na cobertura da mais degradante campanha presidencial desde a democratização do país, com o fim da ditadura civil-militar, em 1985.

João Nery: E nas relações com as instituições jornalísticas?

Juarez Tadeu de Paula Xavier: Esses valores ético-deontológicos têm vigência para toda a sociedade, para as instituições do campo da comunicação e disciplinam suas relações, internas e externas. Nas últimas décadas têm sido observados momentos de convergência e divergência entre as categorias profissionais e 


\section{Princípios com dimensões epistêmicas, sobre a produção de uma informação válida para as relações democráticas, teóricas, sobre a diversidade da cobertura em diversas áreas do saber, técnicas, sobre os procedimentos de captação, edição e difusão de informação, e ético-deontológicos, sobre a responsabilidade social da atividade profissional do jornalista.}

as instituições corporativas, provocadas por aspectos externos, em relação à democracia, e internos, pelas profundas mudanças no locus e logos da atividade profissional que é a redação. Fruto do século XIX, a redação foi essencial para a construção e consolidação dos cânones do jornalismo. Sua fragmentação, virtualização e desterritorialização repercute em toda a lógica da produção jornalística, gerando vários níveis de tensões, agravadas pela desregulamentação da atividades profissional, com o fim da obrigatoriedade do diploma universitário para o exercício profissional e, com essa medida, a impossibilidade de um órgão nacional regulador, a exemplo de outras categorias profissionais, que, sem sombra de dúvidas, daria robustez às relações ético-deontológicas, dentro e fora das redações. Essa decisão afeta os interesses da sociedade, que fica à mercê de decisões éticas "monocráticas" das corporações, sem o escrutínio da sociedade e dos órgãos profissionais, amplificando os ruídos da categoria e da sociedade nas relações com as instituições jornalísticas. Em especial com o aprofundamento de um fenômeno iniciado no século XX, quando as entidades jornalísticas passaram a fazer parte de grandes conglomerados corporativos, como sócios menores, entre um conjunto de interesses econômicos e políticos desses grupos. Algumas vezes, como no exemplo mencionado acima, há o resquício de conflito entre a cobertura e os interesses corporativos desses conglomerados. Esses conflitos se expressam nos interesses dos grandes anunciantes, que compram espaços publicitários e financiam projetos jornalísticos, e com a compra de veículos jornalísticos por bilionários brasileiros, uma tendência mais recente. Entre os cem bilionários brasileiros que frequentam a lista da revista Forbes, há todos os principais anunciantes e os donos dos principais veículos de comunicação, com a replicação desses fenômenos em diversos estados e, dentro desses, em diversas cidades, em que há a confluência dos interesses políticos de grupos e a propriedade de veículos. Sem dúvidas, esse cenário fragiliza as relações dentro e com as entidades corporativas do jornalismo, como tem denunciado o sindicato profissional da categoria.

João Nery: A atividade docente pressupõe uma ética específica?

Juarez Tadeu de Paula Xavier: Creio que sim. A docência é um espaço mediador essencial na formação profissional de uma atividade que implica o Estado democrático de direito e a defesa dos direitos humanos, para assegurar a superação das assimetrias sociais. Ela mo- 
biliza as dimensões do ensino, para o compartilhamento de saberes epistêmicos, teóricos, técnicos e ético-deontológicos, da pesquisa que aproxima os procedimentos e saberes da profissão das fronteiras conceituais e práticas, com o objetivo de superá-las, da extensão para atender demandas sociais no campo do jornalismo, e da gestão para assegurar um projeto político-pedagógico comprometido com a formação de profissionais críticos, infraestrutura compatível com as necessidades da sociedade, e que garanta uma atmosfera política para o debate crítico e democrático. Para exercer esse conjunto de atividades formativas, creio que é necessária uma docência ética, com conhecimentos didáticos e pedagógicos para o ensino superior. A confluência da prática necessária à formação crítica, para que ela não seja estéril, e a formulação teórica e conceitual à formação intelectual, para que ela não seja desinformada e despolitizada, requer uma docência qualificada, atualizada, engajada com o projeto social democrático e inclusivo. Requer, em síntese, uma ética que funda a experiência profissional com a reflexão teórica. Esse modelo, predominante nos últimos anos, tem se mostrado o mais adequado, nas principais instituições de ensino superior do país.

João Nery: A construção da cidadania no Brasil passa por uma ética na comunicação?

Juarez Tadeu de Paula Xavier: Se a função do jornalismo é, no campo liberal, informar à cidadania para que ela seja crítica e tenha liberdade de decidir, a comunicação democrática e o jornalismo crítico são fundamentais para a garantia dos direitos cidadãos. Contra as violações do Estado, responsável pelos vetores coercitivos e persuasivos na sociedade, do mercado, com foco centrado no lucro, e dos segmentos sociais organizadores com acesso, quase que exclusivo, aos capitais econômicos, culturais, sociais e políticos. Há o reconhecimento por parte das organizações multilaterais internacionais, como a Anistia Internacional, e das nacionais, como a Ordem dos Advogados do Brasil, de que a comunicação livre, democrática e com responsabilidades sociais é condição sine qua non para a ampliação do espectro da cidadania, no Brasil e no mundo. Sem jornalismo livre, plural, nas fontes e abordagens, profissional e sustentável não há democracia cidadã. A emergência do jornalismo radical - aquele que procura as raízes dos fenômenos com alto índice de noticiabilidade - tem evidenciado essa necessidade que, com sua prática, tem pautado o jornalismo corporativo, em temas fundamentais, como os direitos dos segmentos sociais em condições de vulnerabilidade, como mulheres, com especial atenção à mulher negra, negros, com especial atenção ao racismo sistêmico, população LGBTQI+, com especial atenção às violências físicas e simbólicas desse grupo social, e população marginalizada, com especial atenção às marcas das desigualdades sociais abissais. Esse jornalismo tem ampliado o escopo das pautas, das coberturas e abordagens, necessárias à construção da ainda frágil cidadania no país.

João Nery: A produção de notícias falsas por jornalistas e instituições jornalísticas contraria a ética que se formulou no jornalismo do século XX?

Juarez Tadeu de Paula Xavier: Sim. As notícias falsas violam os direitos constitucionais e os pressupostos éticos do jornalismo, e corroem a base da democracia, com a formação de uma "esfera pública do ódio", com a crítica infundada às instituições democráticas, a apologia 


\section{Lamentavelmente, no século XXI, há uma produção em escala industrial de mentiras provenientes dos governos que têm afetado negativamente a saúde da população e da democracia.}

às violência em todas as dimensões, com a destruição da reputação de opositores políticos e a tentativa de redução de direitos dos setores em condições de vulnerabilidade social. Prática condenada por órgãos nacionais e internacionais em defesa dos direitos humanos, que pode levar à morte, como está sendo observado na maior crise sanitária dos últimos cem anos, com a sabotagem ao distanciamento social, ao uso de máscaras e com a defesa de "tratamento precoce" contra a infecção do Covid-19 que, além de ineficiente, agrava o quadro da imunização. Lamentavelmente, no século XXI, há uma produção em escala industrial de mentiras provenientes dos governos que têm afetado negativamente a saúde da população e da democracia. Pesquisas indicam que o ex- presidente dos Estados Unidos da América, Donald Trump, e o presidente da República do Brasil, Jair Messias Bolsonaro, produziram e produzem uma quantidade de mentiras diárias que contribuem com o agravamento da pandemia do Covid-19, com a produção de milhares de mortes evitáveis. $\mathrm{O}$ combate às fake news é condição determinante para a consolidação da democracia.

João Nery: É possível estabelecer uma ética das relações nas redes digitais?

Juarez Tadeu de Paula Xavier: Acredito que sim. Porém, a iniciativa deve ser do governo, com a anuência da sociedade, e não prerrogativa das grandes empresas do setor de tecnologia, pois essa ação unilateral pode colocar em risco a privacidade e con- fidencialidade de dados e informações da população. Defendo que a sociedade civil, suas organizações e as instituições do Estado democrático possam debater e deliberar sobre as regulações que assegurem relações éticas nas redes digitais, com sanções às violações de direitos individuais e coletivos. $\mathrm{Na}$ sociedade da informação, com a geração de grandes bancos de dados, concentrados em algumas empresas de tecnologia, a ausência de regulação pode afetar a democracia, como observado nas eleições dos EUA e sobre o Brexit, que determinou a saída do Reino Unido da União Europeia. Sem uma regulação democrática, essa concentração de dados e informações pode, como os exemplos citados, deformar as relações democráticas, com implicações negativas à cidadania.

João Nery: Como docente na área de comunicação, que relação você faz entre ética e deontologia?

Juarez Tadeu de Paula Xavier: Compreendo a ética como o respeito aos direitos constitucionais, que disciplinam minhas relações como cidadão, jornalista e docente, na defesa do Estado democrático de direito, e de uma sociedade justa e igualitária, com responsabilidades deontológicas imprescindíveis, como uma disciplina da ética, ao exercício profissional numa universidade pública, em defesa do ensino superior público, gratuito, democrático, inclusivo, laico e acolhedor. Acredito que o docente no ensino superior tem um mandato con- 
ferido pela sociedade para representá-la na defesa da ciência, cultura e tecnologia acessíveis à sociedade. Portanto, a ética tem, ou deveria ter, uma dimensão "universal", enquanto a deontologia tem, ou deveria ter, uma dimensão particular a cada exercício profissional. Dimensões que interagem e implicam a vigilância permanente dos valores ético-deontológicos em defesa, nas minhas atividades, do Estado democrático de direito e da igualdade social, e do ensino superior crítico e inclusivo, para além das marcas de um modelo de Estado patriarcal, segregacionista, elitista e racista.

João Nery: Considera que as pessoas veem diferenças entre os conceitos?

Juarez Tadeu de Paula Xavier: Não! As suas fronteiras conceituais escapam, muitas vezes, à percepção da sociedade, em especial em um país com baixa participação política e democrática, fruto do passado escravocrata, colonial e de reprodução do apartheid tangível e intangível, que ainda está presente nas relações sociais e políticas do país.
João Nery: O neoliberalismo pode levar a uma ética que coloque em risco a cidadania e a democracia?

Juarez Tadeu de Paula Xavier: Sim! Desde a aderência ao Consenso de Washington, em 1989, setores sociais e empresariais têm se empenhado em fazer a defesa de um conjunto de propostas que desmontam direitos consagrados, desde a adoção dessas políticas no Chile, com o golpe militar em 1973. No Brasil, o avanço dessas medidas desmontou direitos trabalhistas e previdenciários, que condenam os segmentos assalariados a um futuro incerto. Pelas implicações provocadas, e por violar direitos, essas políticas são adotadas em estado de exceção, com a suspensão dos direitos políticos, ou em Estados nacionais que têm cerceado e criminalizado opositores, com o recrudescimento da violência política e do constrangimento das instituições democráticas. A experiência tem mostrado que a política neoliberal é incompatível com a democracia, com os direitos sociais e humanos, em especial para os segmentos mais vulneráveis da sociedade.

Data de recebimento: 31/03/2021

Data de aceite: $15 / 04 / 2021$

Dados dos autores:

\section{Juarez Tadeu de Paula Xavier}

http://lattes.cnpq.br/3036916968393237

Graduado em Comunicação Social Jornalismo pela Pontifícia Universidade Católica de São Paulo (1990), mestre em Ciências da Comunicação pela Universidade de São Paulo (2000) e doutor em Ciências da Comunicação pela Universidade de São Paulo (2004). Atualmente é professor assistente doutor da Universidade Estadual Paulista "Júlio de Mesquita Filho" - UNESP. Tem experiência na área de Comunicação, com ênfase em Jornalismo Especializado (Comunitário, Rural, Empresarial, Científico), atuando principalmente nos seguintes temas: economia criativa, afrodescendentes, racismo, etnocídio, fundamentos do jornalismo, jornalismo especializado e educação e diversidade racial.

\section{João Elias Nery}

http://lattes.cnpq.br/9623082644225542

Graduado em Comunicação Social - habilitação Produção Editorial pela Universidade Anhembi-Morumbi, mestre em Comunicação Social pela Universidade Metodista de São Paulo e doutor em Comunicação e Semiótica pela Pontifícia Universidade Católica de São Paulo. É professor da Fapcom. 